\title{
Monoacylglycerols and diacylglycerols for fat-based food products: a review
}

\author{
*Subroto, E. \\ Department of Food Industrial Technology, Faculty of Agro-Industrial Technology, Universitas \\ Padjadjaran, Jalan Raya Bandung-Sumedang Km. 21, Jatinangor, Sumedang 40600, Indonesia
}

\begin{abstract}
Article history:
Received: 27 November 2019

Received in revised form: 3

January 2020

Accepted: 5 January 2020

Available Online: 21 January 2020
\end{abstract}

\section{Keywords:}

Monoacylglycerol,

Diacylglycerol,

Structured lipids,

Fat based food product

\section{DOI:}

https://doi.org/10.26656/fr.2017.4(4).398

\begin{abstract}
The flexibility of monoacylglycerol (MAG) and diacylglycerol (DAG) attracted the attention of researchers to learn more about MAG and DAG in food science and technology. The objective of this paper is to serve a review or summarize the production (especially enzymatic glycerolysis), characteristics, and application of MAG and DAG, especially for fat-based products. The characteristic of MAG and DAG related to melting and crystallization properties, polymorphism, microstructure, and rheology are presented and discussed. The applications of MAG and DAG include their use as fats/oils rich in MAG and DAG, margarine/shortening, surfactant/emulsifier, and organogels are also provided. Various studies have shown that MAG and DAG can improve the characteristics of various fat-based food products.
\end{abstract}

\section{Introduction}

Structured lipids (SLs) are lipids that have been modified in the composition of fatty acids or the distribution of fatty acid positions through chemical or enzymatic reactions. The scope of "lipids" includes acylglycerols, such as triacylglycerols (TAGs), diacylglycerols (DAGs), monoacylglycerols (MAGs) and phospholipids (Kim and Akoh, 2015). Research on SLs is growing rapidly, including monoacylglycerol and diacylglycerol (MAG and DAG) due to their nature as a versatile emulsifier. MAG and DAG can also improve the physical and functional characteristics of lipids, including crystallization and melting properties, solid fat content, texture and rheology, microstructure, and polymorphism (Saberi et al., 2012; Chen et al., 2014; $\mathrm{Ng}$ et al., 2014). MAG and DAG can also improve the oxidative properties of fats/oils (Gomes et al., 2010; Nderitu et al., 2018). MAG and DAG, especially in the form of 1,3-DAG, also have better nutritional value than TAG (Lo et al., 2008; Feltes et al., 2013).

MAG and DAG can be synthesized through partial hydrolysis of fat/oil (TAG), partial esterification of free fatty acids with glycerol, and glycerolysis of fats/oils with glycerol (Gunstone, 1999; Devi et al., 2008; Feltes et al., 2013). Partial hydrolysis has difficulty in controlling the hydrolysis reaction; yields are relatively low and require large amounts of oils/fats. Partial esterification between glycerol and free fatty acids is another strategy to obtain MAG and DAG, but this reaction is reversible for re-hydrolysis. However, MAG and DAG are produced more effectively by glycerolysis between oil/fat (TAG) and glycerol. Glycerol can be obtained easily and abundantly from the byproducts of biodiesel processing in the form of glycerin so that the production of MAG and DAG through glycerolysis process is more attractive because of the cheapness of raw materials (Phuah et al., 2015). Glycerolysis produces high yields because each mole of TAG can produce 3 moles of MAG. Glycerolysis can also be directed to the formation of DAG by reducing glycerol as a substrate (Bornscheuer, 1995; Subroto et al., 2019).

MAG and DAG have been widely used in food, such as healthy oil-rich in DAG (Lo et al., 2008; Ferretti et al., 2018), shortening (Latip et al., 2013), soft tub margarine (Saberi et al., 2012), organogels (Yilmaz and Ögütcü, 2014; Lopez-Martínez et al., 2015), and fatty emulsion (Kowalska et al., 2014). MAG and DAG are also widely used as an emulsifier in various emulsionbased products. Besides, they can improve polymorphic transitions, susceptibility to fat bloom, emulsion stability, and oxidation (Schantz and Rohm, 2005; Smith et al., 2011). The utilization of MAG and DAG continues to develop in the application of fat/oil products with special properties by modifying the source of fats/ oils and the types of fatty acids. 


\section{Methods for MAG and DAG production}

Of all the methods for producing MAG and DAG, glycerolysis is the method that theoretically gives the highest yield (Feltes et al., 2013). Glycerolysis can also utilize glycerin which is a biodiesel industry waste (Ferrão et al., 2017). On an industrial scale, MAG and DAG are generally produced through continuous glycerolysis of fat/oil using alkaline inorganic catalysts, high temperature $\left(220-260^{\circ} \mathrm{C}\right)$, and an inert gas (Damstrup et al., 2005).

MAG and DAG production can also be carried out with enzymatic catalysis, which gets attention because it does not require high temperatures (mild reaction), the lipids are not easily degraded, and the products are easily purified and are environmentally friendly. The lipase selectivity property also has the potential to obtain suitable products such as structured lipids (Gunstone, 1999). Lipase immobilization with chemical or physical modification can also increase its catalytic and can be easily separated and reused to reduce production costs and become a competitive biocatalyst to be applied to the industry (Villeneuve et al., 2000; Osborn and Akoh, 2002).

MAG products or DAGs that are obtained subsequently need to be separated or purified, including through separation based on the formation of a solid phase resulting from glycerolysis. Melting points generally increase TAG, DAG, and MAG sequentially and decrease with increasing unsaturation of the fatty acids making up acylglycerol (Pawongrat et al., 2008). Product separation can be carried out by fractionation at cold temperatures so that lipids with high melting points will crystallize and produce a solid phase. Separation of the solid fraction will separate the acylglycerols obtained. Separation or purification of MAG or DAG can also use molecular distillation, which is especially suitable for separating and purifying heat-sensitive and liquid-shaped products at low air pressure. This method can produce MAG with a purity of up to $90 \%$ (Corma et al., 2007; Wang et al., 2010).

\section{Enzymatic glycerolysis}

Enzymatic glycerolysis has the advantage that the reaction temperature is relatively low, the substrate is not degraded, purification of the product is easier and more environmentally friendly than chemical glycerolysis (Phuah et al., 2015). Enzymatic glycerolysis only requires small amounts of water. Therefore, enzymes should be in an immobilized form. Besides, immobilized enzymes can be used repeatedly and have better stability (Osborn and Akoh, 2002). The enzymatic glycerolysis reaction is affected by several factors. These factors include the type of stirrer in the reactor (Phuah et al., 2015; Subroto et al., 2020). Stirrer serves to accelerate the occurrence of enzyme contact with the substrate. Fat/ oil and glycerol substrate do not dissolve each other. Thus a solvent is needed to dissolve it. Glycerol used as a substrate can increase the rate of the reaction but is too large a number to inhibit the reaction (Krüger et al., 2010). The amount of enzyme/catalyst used can also accelerate the reaction to a certain concentration (Naik et al., 2014; Subroto et al., 2019).

Enzymatic glycerolysis can be directed to the formation of monoacylglycerol (MAG) and diacylglycerol (DAG), mainly by determining the amount of glycerol. Glycerolysis leads to the formation of MAG in excess glycerol conditions, whereas the reaction leads to the forming of DAG when the amount of glycerol is limited. Naik et al. (2014) investigated the glycerolysis of sunflower oil for MAG production obtaining an optimum amount of glycerol used at a oil to glycerol molar ratio of 1:5, whereas Wang et al. (2011) producing DAG through enzymatic glycerolysis of soybean oil obtained optimum conditions of oil to glycerol molar ratio of about 2:3.

In the process of glycerolysis using immobilized lipase therein consists of a hydrophobic component (oil/ fat), hydrophilic component (glycerol), and an enzyme in the form of a solid phase. In such systems, it is imperative to pay attention to the low solubility between the substrate (glycerol and fat/oil) (Pawongrat et al., 2007). Nevertheless, MAG and DAG obtained during the reaction can act as emulsifiers, increase the mixing between the two substrates and increase conversion rate. Under these conditions, glycerolysis can be carried out without the addition of solvents or other additives, but the results obtained are less than optimal due to the low solubility of the two-phase system (Torres et al., 2002). An alternative way to disperse immiscible substrates is the use of surfactants, which are molecules that have amphipathic characteristics to form micelle systems. The use of surfactants in the glycerolysis system, followed by rapid stirring, can create an interfacial area, increasing contact between the substrate and enzymes, thereby increasing MAG and DAG products (Bornscheuer, 1995).

Enzymatic glycerolysis can also be conducted in various reaction systems, such as by forming micelles. The reaction is slower when glycerolysis is undertaken on a solvent-free system (Yang et al., 2003; Valério et al., 2009). These problems can be overcome by using organic solvents or on systems containing surface-active materials or surfactants (Yang et al., 2005; Pawongrat et al., 2007). The use of surfactants or solvents as reaction 
media will reduce reaction time and increase conversion, so it is potential for industrial-scale application (Feltes et al., 2013).

The alternative to overcome the low substrate solubility in glycerolysis is to use a suitable solvent and produce a homogeneous system that increases mass transfer, decreases reaction time, and increases product conversion. In such systems, t-butanol are extensively used because they produce high products in a short time. Naik et al. (2014) investigated glycerolysis of sunflower oil for the production of monoacylglycerol with the lipase catalyst $C$. antarctica using several types of organic solvents and found that t-butanol is the best solvent. Wang et al. (2011), on the other hand, examined the glycerolysis of soybean oil for the production of diacylglycerol using $C$. antarctica lipase in the t-butanol system obtained by the substrate concentration in the optimum t-butanol solvent at a concentration of $40 \%$.

In general, the reaction media are critical in enzymatic glycerolysis because they can overcome the low miscibility of the substrates. The use of solvents makes the reaction system homogeneous, decreases the viscosity of the reaction mixture, increases the diffusion of the substrate, and increases the reaction rate (Tripathi et al., 2006; Subroto et al., 2019). Several studies have shown that differences in solvent polarity also affect lipase selectivity in catalyzing reactions. Some organic solvents provide a protective effect on lipase so that it is more stable to heat (Goldberg et al., 1990).

The catalytic activity of lipases is efficient in organic solvents. When an enzyme is in an organic environment, its properties can change like its chemo- and stereoselectivity, increase its stability, and increase its rigidity. The higher the amount of the solvent, the higher the mass transfer and the lower the viscosity of the reactants (Naik et al., 2014). The selection of organic solvents must pay attention to the solubility of the substrates in the solvent, and it has to be inert in the reaction. Other factors that may need to be considered are density, toxicity, viscosity, surface tension, and cost (Feltes et al., 2013). Naik et al. (2014) found that for enzymatic glycerolysis between oil and glycerol, $\mathrm{t}$ butanol and t-pentanol are better solvents than hexane, heptane, acetone, ethanol, methanol, acetonitrile, and chloroform.

Lipase from $C$. antarctica $B$ (CALB) is an excellent biocatalyst for the glycerolysis reaction. This enzyme catalyzes a variety of different substrates and shows good performance (Torres et al., 2002). CALB has excellent activity in the presence of solvents and surfactants (Feltes et al., 2013). The use of CALB for the glycerolysis reaction is almost the same as the interesterification reaction in general, which is $5-15 \%$. Naik et al. (2014) reported that glycerolysis of sunflower oil for monoacylglycerol production obtained the optimum conditions at a CALB concentration of $15 \%$. Subroto et al. (2019) found that glycerolysis of palm stearin and palm olein mixture using CALB was optimal at a concentration of $15 \%$.

Lipase concentration can increase the rate of glycerolysis reaction, but the use of enzymes at concentrations that are too high can inhibit the reaction, especially if using an immobilized lipase in the form of solids. Naik et al. (2014) found that high enzyme concentrations could cause the active site of enzyme molecules not to be exposed to the substrate. Besides, protein aggregation tends to occur easily. Immobilized lipases in large quantities also cause less effective agitation, which affects the limitations of mass transfer (Krüger et al., 2010; Subroto et al., 2019). Another problem of enzymatic glycerolysis is the forming of a hydrophilic glycerol layer that envelops an immobilized lipase using a hydrophilic matrix, thus inhibiting contact with the hydrophobic oil phase (Kristensen et al., 2005). It is necessary to choose an enzyme that is hydrophobic matrix so that it can catalyze glycerolysis optimally and obtain more product conversion (Phuah et al., 2015).

Enzymatic glycerolysis is affected by various factors such as the type and amount of substrates, temperature, the use of solvents, and catalyst concentration. Substrate composition affects the rate of glycerolysis using lipases. Increasing the amount of substrate does not always increase the rate of the reaction. The use of an excessive amount of substrate will occur in substrate inhibition. In the glycerolysis reaction, the composition or substrate ratio between oil and glycerol affected the lipase activity, reaction rate, and product conversion. Naik et al. (2014), Wang et al. (2011), and Subroto et al. (2019) found that the addition of glycerol increased the rate of reaction and led to MAG formation rather than DAG, but excessive glycerol addition inhibited the conversion of TAG to MAG and DAG.

The glycerolysis reaction is also affected by the reaction temperature. Increasing the reaction temperature will increase the reaction rate, but too high a temperature can decrease the reaction rate and cause denaturation of the enzyme (Willis and Marangoni, 2002). The high temperature is not needed in a system that contains organic solvents because the hydrophobic substrate dissolves easily. Enzymes are proteins whose stability is related to the three-dimensional structure of proteins. The integrity of the three-dimensional structure on the active side is very important to maintain enzyme activity, and integrity is very much affected by the reaction 
temperature (Whitaker, 1994). Immobilization maintains lipases in conformation, which decreases the ease of enzymes denatured by heat. The optimal temperature for most immobilized lipases is $30-62^{\circ} \mathrm{C}$. Subroto et al. (2008) obtained that the optimum temperature of enzymatic acidolysis of fish oil with lauric acid is 40 $50^{\circ} \mathrm{C}$. Naik et al. (2014) and Wang et al. (2011), who carried out enzymatic glycerolysis using immobilized lipase from $C$. antarctica as a catalyst, obtained that the optimal temperature was reached at $50^{\circ} \mathrm{C}$.

\section{The characteristics of monoacylglycerol and diacylglycerol}

MAG and DAG have different properties compared to TAG. Some characteristics such as melting and crystallization, polymorphism, microstructure, and rheology of a fat/oil are affected by the presence of MAG and DAG, as shown in Table 1.

\subsection{Crystallization and melting characteristic}

The minor lipid components, including MAG and DAG, affect the melting and crystallization characteristics of fats/oils (Smith et al., 2011). These thermal characteristics are usually analyzed by differential scanning calorimeter (DSC) and are shown by a thermogram profile. MAG has faster crystal formation than DAG, and DAG has faster crystal formation than TAG (Basso et al., 2010; Normah et al., 2014). Fats/oils that have MAG and DAG at high concentrations or are added from the outside display more peaks of exothermic transitions, where the peaks are at a higher temperature than native fats/oils. $\mathrm{Ng}$ et al. (2014) and Saberi et al. (2012) reported that differences in the crystallization profiles were mainly due to the content of different acylglycerols structures (MAG, DAG, and TAG). MAG and DAG also have higher heats of crystallization $(\Delta \mathrm{H})$ than TAG. Saberi et al. (2011) compared palm-based oils and palm-based diacylglycerol oils. It was found that $\Delta \mathrm{H}$ palm-based diacylglycerol was higher in all fractions. Crystallization characteristics can further affect the texture of fat. Increasing the MAG and DAG content in fat accelerates the process of crystal formation and creates a harder texture (Basso et al., 2010; Saberi, Tan and Lai, 2011).

Generally, MAG and DAG have a higher melting point than TAG. Saberi, Tan and Lai (2011) showed that in palm oil added to palm oil-DAG (PO-DAG), the peak endotherm of DAG increased in intensity and the peak shifted to a higher temperature. The results showed that palm oil added with palm-based diacylglycerols (PDAG) had more melting peaks and at higher temperatures. Therefore, MAG and DAG can be utilized for the formation of fats/oils products that have faster crystallization and higher melting points than their natural fats/oils.

\subsection{Solid fat content}

In general, MAG and DAG have higher melting points and have implications for increasing SFC. MAG and DAG have SFC profiles with slower SFC declines than TAG and experience perfect melting $(\mathrm{SFC}=0)$ at temperatures higher than TAG. Saberi et al. (2011) compared the SFC profile of palm-based diacylglycerols in various types of fractions with palm-based oils. It was found that the SFC profile in palm-based diacylglycerol has a higher SFC than palm-based oils especially at temperatures above $15^{\circ} \mathrm{C}$. SFC in rich-in fats MAG or DAG which was gradually melted shows a relatively more uniform consistency at various temperatures, making it more suitable for plastic-fat products such as margarine and shortening (Nor Aini et al., 2002). Romain et al. (2013) obtained monoacylglycerols from Nephelium lappaceum L. oil, showing that MAG fractions at various purification levels had significantly higher SFC at all temperatures. Naderi et al. (2016) reported that the addition of MAG (monopalmitin) above $0.5 \%$ increased the SFC of structured chicken fat at all temperatures. This shows that increasing the proportion of MAG results in the formation of a crystalline network that is more resistant to temperature; this can be

Table 1. Changes in MAG and DAG characteristics compared to TAG

\begin{tabular}{|c|c|c|}
\hline Characteristics & Changes in characteristics & References \\
\hline Crystallization & $\begin{array}{ll}\text { - } & \text { Faster crystallization } \\
\text { - } & \text { Higher temperature } \\
\end{array}$ & (Basso et al., 2010; Saberi et al., 2011; Normah et al., 2014) \\
\hline Melting & $\begin{array}{ll} & \text { Slower Melting } \\
\text { - } & \text { Higher temperature }\end{array}$ & (Basso et al., 2010; Saberi et al., 2011) \\
\hline Solid fat content & - Higher solid fat content & (Saberi et al., 2012; Ng et al., 2014) \\
\hline Polymorphism & - $\beta$-crystal $>>\beta^{\prime}$-crystal & (Saberi, Tan and Lai, 2011; Saberi et al., 2011; Zhang et al., \\
\hline Microstructure & $\begin{array}{lc}\text { - } & \text { Smaller crystal } \\
\text { - } & \text { More homogeneous } \\
\text { - } & \text { Needle-like crystals }\end{array}$ & (Maruyama et al., 2014; Xu et al., 2016; Naderi et al., 2016) \\
\hline Rheology & - $\quad$ Higher viscosity and elasticity & (Rocha-Amador et al., 2014; Naderi et al., 2018) \\
\hline Texture (Hardness) & $-\quad$ Harder & (Saberi, Tan and Lai, 2011; Subroto et al., 2019) \\
\hline
\end{tabular}


attributed to the fat crystal structure which is denser at the addition of high MAG (Basso et al., 2010; Maruyama et al., 2014). Ng et al. (2014) studied palm olein-based diacylglycerol blended with palm olein, and their SFC increased with the proportion of palm oleinbased diacylglycerol at all temperatures. Saberi et al. (2012) also showed that in making soft tub margarine, the addition of palm-based diacylglycerol to a mixture of sunflower oil and palm kernel olein increased their SFC at all temperatures.

\subsection{Polymorphism}

The presence of MAG and DAG can affect polymorphism in fats/oils. Most of the fats/oils composed by TAG have the form of $\beta^{\prime}$ crystals, but the presence of MAG and DAG stimulates the formation of $\beta$ crystals. Basso et al. (2010) reported that the addition of MAG to palm oil induces the formation of $\beta$ crystals. The addition of MAG and DAG causes the formation of crystalline nuclei in large quantities and accelerates the process of forming $\beta$ crystals. Zhang et al. (2014) obtained that monoacylglycerol from glycerolysis of partially hydrogenated corn oil changed the type of crystal that was originally $\beta^{\prime}$-crystal to $\beta$-crystal. The MAG and DAG acted as crystallization sites for the initial crystallization in the $\alpha$-crystal then switched to a $\beta$ -crystal due to the improved stability of the crystalline structures. Saberi, Tan and Lai (2011) found that the addition of palm-based diacylglycerol to palm oil showed that the higher the palm-based diacylglycerol was added $(>40 \%)$, the more the palm oil mixture containing high DAG was dominated by $\beta$ crystals $\left(\beta>>\beta^{\prime}\right)$. Saberi et al. (2011) also described that the crystalline form of various palm-based diacylglycerol fractions obtained the majority of crystals in the $\beta$-form. The presence of MAG and DAG acts as an accelerator in the process of crystallization of fat, then leads to the formation of $\beta$ crystals. However, the presence of MAG produces higher $\beta$ crystals compared to DAG (Chen et $a l ., 2014)$. This $\beta$ crystal is very important, especially in the chocolate industry which requires fat crystals in the form of $\beta$.

\subsection{Microstructure and crystalline morphology}

The presence of acylglycerol (MAG and DAG) can affect the morphology of the crystal and its microstructures. Microstructures of crystals can be seen using polarized light microscopy. MAG and DAG stimulate the formation of a large number of small crystal nuclei, causing an increase in the number of crystals, and a decrease in the crystal induction period (Foubert et al., 2004). Basso et al. (2010) reported that the addition of MAG to palm oil causes an increase in the number of crystals because MAG plays a role in increasing the formation of crystalline nuclei that are dispersed in palm oil. Maruyama et al. (2014) added monoacylglycerols 1-3\% to palm oil and coconut oil and showed that greater MAG addition caused smaller spherulite crystal size. Fat crystal dispersions with small size can provide desirable characteristics such as good spreadability and can inhibit the formation of grainy mouthfeel (Herrera et al., 1998). Spreadability is an important characteristic of fat-based products such as butter and margarine (Rønholt et al., 2013; Subroto et al., 2018). Naderi et al. (2016) reported that the addition of MAG to the structuring of chicken fat increased the crystallized fat. The increasing MAG concentrations indicating denser structures with higher crystalline amounts of crystallized fat were seen at all temperatures $\left(5-40^{\circ} \mathrm{C}\right)$. Likewise, $\mathrm{Xu}$ et al. (2016) reported that the morphology of crystals from palm oil and palm olein enriched with DAG showed a more homogeneous microstructure with a small form of needle-like crystals. Normah et al. (2014) reported that the addition of $6 \%$ DAG to palm oil caused nucleation quickly with a smaller size in palm oil.

\subsection{Rheology}

MAG and DAG have different rheological characteristics than TAG (fat/oil). Shakerardekani et al. (2013) reported that monoacylglycerol addition changed the rheological behavior of pistachio spread. The addition of $1.5 \%$ of monoacylglycerols increased the work of shear, which indicated good spreadability. Monoacylglycerols affected the rheological characteristic of pistachio spreads. Products containing monoacylglycerols showed a higher storage modulus than loss modulus. Naderi et al. (2018) studied the effect of monoacylglycerols on rheological properties of canola oil and reported that MAGs addition increased the viscosity, elasticity and complex moduli, and the complex viscosity. The products are suitable for the production of liquid margarine and shortenings. Phuah et al. (2016) studied rheological properties of palm kernelbased diacylglycerol-enriched mayonnaise, showed that rheological properties of mayonnaise displayed similar gel-like behavior with higher storage modulus and loss tangent less than 0.3 . The product was suitable for healthy mayonnaise formulation. Rocha-Amador et al. (2014) reported that commercial saturated monoacylglycerol and mono-/diacylglycerol mixtures affected the rheological of organogels from vegetable oils. The addition of MAG and MAG-DAG mixtures $(10 \%)$ increased the value of elastic modulus $\left(G^{\prime}\right)$ which is associated with the solid behavior of the products. MAG and DAG organized a more stable structural configuration, due to the ease of contact between molecules, which decreases the energy needed for self- 
organization and compactness of structure (Mazzanti et al., 2003).

\section{Utilization and application of monoacylglycerols and diacylglycerols}

MAG and DAG are extensively used in the food, pharmaceutical and cosmetics industries, especially since it is known that MAG and DAG have no irritating effect on the skin compared to other ionic surfactants. MAG and DAG, specifically 1,3-DAG have positive health effects such as preventing cardiovascular disease, which makes MAG and DAG attractive produced mainly for pharmaceutical applications (Bornscheuer, 1995). MAG and DAG can be used separately or simultaneously (a mixture of MAG and DAG). MAG is the most polar compound among simple lipids. Nutritionally, MAG has similarities with TAG. MAG is completely digested and is not restricted to normal digestion (Feltes et al., 2013). MAG containing oleic acid has antioxidant, antiatherogenic, and antidiabetic properties (Cho et al., 2010). This acylglycerol can inhibit the increase of TAG in the blood. MAG, both in the form of sn-1 (3) and sn-2 adjust the increase in insulin levels in the blood after digesting food to prevent obesity and diabetes due to hyperglycemia (Feltes et al., 2013).

MAG is produced mainly as an emulsifier because of its better emulsification ability than DAG. Nonetheless, industrial DAG production is more attractive than MAG, especially due to its good health effects (Feltes et al., 2013). DAG used as a surfactant can be applied to water in oil (W/O) emulsions such as margarine, spread, creamy filling, confectionary products, and shortening (Lo et al., 2008). DAG-rich oil is also known to have beneficial physiological effects. The caloric value and absorption coefficient of DAG are almost the same as TAG. However, DAG specifically in the form of 1,3DAG can act against cholesterol and triglyceride in the blood to inhibit obesity and prevent or reduce fat accumulation in the body (Taguchi et al., 2001).

The versatility of MAG and DAG can be used or applied to a variety of fat-based products, including MAG/DAG-enriched fats/oils, shortening and margarine, surfactants/emulsifiers, and organogels as shown in Table 2.

\subsection{MAG/DAG-enrich fats/oils}

MAG and DAG are found naturally in fats/oils in small amounts. Nevertheless, MAG and DAG can be used to make MAG/DAG-enriched fats/oils that are safe and are even good for health (Lo et al., 2008; Feltes et al., 2013). Zhang et al. (2018) synthesized 2-MAGs rich in PUFAs by enzymatic ethanolysis of tuna oil. Under the optimal conditions, $27 \%$ of 2-monoacylglycerols was obtained. The crystallization used acetonitrile and hexane concentrated $81.13 \%$ and $74.29 \%$ PUFA, respectively, with over $90 \%$ in the forms of 2 monoacylglycerol, which is good for health. Zhang et al. (2017) produced the highly unsaturated monoacylglycerol and diacylglycerol oils through enzymatic esterification and glycerolysis of oleic acid and corn oil. The product contained $46.67 \mathrm{wt} \%$ of MAGs and $35.56 \mathrm{wt} \%$ DAGs, respectively, which is suitable for palm oil-based shortening. Ferretti et al. (2018) synthesized diglycerides rich oil from edible vegetable oils by glycerolysis using $\mathrm{MgO}$ as a basic catalyst. The results showed a product containing $54 \%$ of DAG, $67 \%$ of which is the healthier 1,3-DAG. Yeoh et al. (2014) produced diacylglycerol enriched palm olein through glycerolysis of palm olein, which was then purified by molecular distillation. The results showed that the product has a higher slip melting point and a lower iodine number than its raw material. Saberi et al. (2011) synthesized palm-based diacylglycerols (P-DAG) oils by enzymatic glycerolysis of palm-based oil. The results showed that the products containing DAG of $83-90 \%$ had significantly different physicochemical properties compared to palm-based oils. Cheong et al. (2007) produced a diacylglycerol-enriched palm olein through enzymatic hydrolysis. The product contained $60 \%$ of DAG and $40 \%$ of TAG, which is suitable for shortening and margarine.

Modified fats/oils or structured lipids rich in MAG and DAG continue to develop along with the various functional advantages of MAG and DAG. MAG and DAG-rich structured lipids are generally synthesized via glycerolysis in one type of fat/oil (Feltes et al., 2013). Synthesis of structured lipids rich in MAG and DAG by combining reactions in more than one type of fats/oils has several advantages because the SLs produced are rich in MAG and DAG, as well as having the physicochemical characteristics or desired melting profile depending on the type of fats/oils. Kowalska et al. (2014) successfully synthesized structured lipids rich in MAG and DAG as "fatty emulsion" from a mixture of mutton tallow and rapeseed oil through a combination of interesterification and partial hydrolysis reactions in one reaction system. Subroto et al. (2019) synthesized structured lipids rich in MAG and DAG through glycerolysis-interesterification of a mixture of palm stearin and palm olein. It obtained structured lipids which had better emulsion capacity and stability and higher melting point than physical blending.

\subsection{Shortening and margarine}

Various types of modifications to shortening and margarine have been successfully produced by making 
Table 2. MAG and DAG applications in various fat-based products.

\begin{tabular}{|c|c|c|}
\hline Products & Source of MAG/DAG & References \\
\hline \multirow{6}{*}{ MAG-DAG Fats/Oils } & Corn oil & (Zhang et al., 2017) \\
\hline & Vegetable oils & (Ferretti et al., 2018) \\
\hline & Palm olein & (Yeoh et al., 2014; Cheong et al., 2007) \\
\hline & Palm-based oils & (Saberi et al., 2011) \\
\hline & Mutton tallow and rapeseed oil & (Kowalska et al., 2014) \\
\hline & Palm stearin and palm olein & (Subroto et al., 2019) \\
\hline \multirow{4}{*}{ Margarine/shortening } & Palm mild fraction & (Latip et al., 2013) \\
\hline & Sunflower oil, palm kernel olein & (Saberi et al., 2012) \\
\hline & Canola oil & (Naderi et al., 2018) \\
\hline & Chicken fat & (Naderi et al., 2016) \\
\hline \multirow{3}{*}{ Surfactant/emulsifier } & Palm based oils/fats & (Fu et al., 2018) \\
\hline & Palm oils & (Hattori et al., 2015) \\
\hline & Vegetable oil & (Maruyama et al., 2014) \\
\hline \multirow{3}{*}{ Organogels } & Monostearate & (Ferro et al., 2019) \\
\hline & Monostearate and monopalmitate & (Rocha-Amador et al., 2014; Lopez-Martínez et al., 2015) \\
\hline & Saturated fat & (Yilmaz and Öğütcü, 2014; Pérez-Martínez et al., 2019) \\
\hline
\end{tabular}

various types of fats/oils and using acylglycerol (MAG and DAG). DAG is suitable for use in making fat products in the form of water-in-oil emulsions. Stearin fraction of palm-based diacylglycerol (PDAGS) used for the production of bakery shortening obtained that a mixture of PDAGS and palm mild fraction (PMF) produced bakery shortening with characteristics of better structural compatibility and full miscibility with mixed crystals $\beta+\beta^{\prime}$ polymorphs (Latip et al., 2013). The saturation of fatty acids in MAG and DAG also affects the storage stability of the resulting shortening. MAG and DAG which are rich in unsaturated fatty acids are known to decrease the crystallization rate, improved stability of $\beta^{\prime}$ crystals, and produce a more stable hardness (Zhang et al., 2017). DAG can also be used for making margarine. Saberi et al. (2012) produced palmbased diacylglycerol-enriched soft tube margarine from a mixture of palm-based diacylglycerol, sunflower oil, and palm kernel olein with a ratio of 50/35/15. It obtained margarine with a similar SFC profile, but saturated fatty acids are lower compared to commercial margarine. Naderi et al. (2018) utilizing MAG in making liquid margarine and shortening from canola oil obtained products suitable for use in bakery. MAG from palm oil can also be mixed with chicken fat to get structured chicken fats that can be applied to produce soft tub margarine and Iranian vanaspati (Naderi et al., 2016)

\subsection{Surfactant/emulsifier}

MAG and DAG are compounds containing hydrophilic and hydrophobic groups making them emulsifiers that can form stable and homogenous emulsions (Devi et al., 2008). MAG and DAG supply about $75 \%$ of the world's emulsifier production for food (Feltes et al., 2013). MAG is widely used in bakery, margarine, milk and confectionery products, especially as an emulsifying agent and stabilizer (Damstrup et al., 2005). For applications as food emulsifiers, MAG should have a high purity because MAG has better emulsification properties compared to mixtures of different acylglycerols (Bornscheuer, 1995). MAG is often used as an emulsifier, where the use of $0.5 \%$ by weight of the material is usually obtained by a stable emulsion (Feltes et al., 2013). Fu et al. (2018) using MAG and DAG as emulsifiers in shortening for cake making, found that MAG and DAG encourage inclusion and retention of air in cake dough, thereby increasing the volume and structure of cake crumbs. Emulsifiers, in general, can improve the hardness, compactness, suppleness, and the level of staling in cakes (Paraskevopoulou et al., 2015). MAG, as an emulsifier also has the ability to form complexes with starch, which can improve the quality of bread, such as firmness and hardness (Hattori et al., 2015). MAG and DAG act as emulsifiers, which can inhibit fat bloom, as it is known that emulsifiers can prevent susceptibility to fat bloom that often occurs in chocolate products (Dhonsi and Stapley, 2006; Smith et al., 2011).

\subsection{Organogels}

Lipid organogels are an alternative to getting semisolid fat by reducing the proportion of saturated fatty acids, making them safer for health (Chaves et al., 2018). MAG and DAG can improve organogel microstructure of vegetable oil with better intermolecular forces (Rocha -Amador et al., 2014). The use of MAG in the form of glyceryl monostearate has been proven to be able to improve the crystals and texture of oleogels (Ferro et al., 2019). Lopez-Martínez et al. (2015) developed MAGorganogel with and without ethylcellulose from 
vegetable oil. The results showed that there was a synergistic interaction between MAG and ethylcellulose, which resulted in organogels with lower oil loss and better viscoelastic properties than without ethylcellulose. Yilmaz and Öğütcü (2014) developed hazelnut oil organogels with beeswax and MAG as organogelators. It was found that the higher the organogelators, the faster the formation of crystals and SFC increased. The organogels obtained are also more resistant to oxidation and can be used as a basis for margarine and shortening. Pérez-Martínez et al. (2019) also showed that MAG can act as nucleation sites but does not affect the thermodynamic stability of candelilla wax oleogels. Thus, MAG and DAG have the potential to improve oleogel and organogel products

\section{Conclusion}

MAG and DAG can improve various physicochemical properties of fats/oils for various purposes that require higher melting and crystallization temperatures, fat crystals in the form of $\beta$, smaller and homogeneous crystallite sizes, and harder textures or higher viscosities. MAG and DAG have been widely applied in various fat-based products and improve the characteristics of products such as MAG/DAG-enriched fats/oils, margarine/shortening, surfactants, and organogels.

\section{Conflict of Interest}

The author declares no conflict of interest.

\section{Acknowledgments}

The author would like to thank the Rector of Universitas Padjadjaran for the support provided; as well as The Ministry of Education and Culture of the Republic of Indonesia.

\section{References}

Basso, R.C., Ribeiro, A.P.B., Masuchi, M.H., Gioielli, L.A., Gonçalves, L.A.G., Santos, A.O. dos, Cardoso, L.P. and Grimaldi, R. (2010). Tripalmitin and monoacylglycerols as modifiers in the crystallisation of palm oil. Food Chemistry, 122(4), 1185-1192. https://doi.org/10.1016/j.foodchem.2010.03.113

Bornscheuer, U.T. (1995). Lipase-catalyzed syntheses of monoacylglycerols. Enzyme and Microbial Technology, 17(7), 578-586. https:// doi.org/10.1016/0141-0229(94)00096-A

Chaves, K.F., Barrera-Arellano, D. and Ribeiro, A.P.B. (2018). Potential application of lipid organogels for food industry. Food Research International, 105,
863-872.

https://doi.org/10.1016/

j.foodres.2017.12.020

Chen, B., Mcclements, D.J. and Decker, E.A. (2014). Impact of diacylglycerol and monoacylglycerol on the physical and chemical properties of stripped soybean oil. Food Chemistry, 142, 365-372. https:// doi.org/10.1016/j.foodchem.2013.07.070

Cheong, L.Z., Tan, C.P., Long, K., Affandi Yusoff, M.S., Arifin, N., Lo, S.K. and Lai, O.M. (2007). Production of a diacylglycerol-enriched palm olein using lipase-catalyzed partial hydrolysis: Optimization using response surface methodology. Food Chemistry, 105(4), 1614-1622. https:// doi.org/10.1016/j.foodchem.2007.03.070

Cho, K.-H., Hong, J.-H. and Lee, K.-T. (2010). Monoacylglycerol (MAG)-oleic acid has stronger antioxidant, anti-atherosclerotic, and protein glycation inhibitory activities than MAG-palmitic acid. Journa of Medicinal Food, 13, 99-107. https:// doi.org/10.1089/jmf.2009.1024

Corma, A., Iborra, S. and Velty, A. (2007). Chemical routes for the transformation of biomass into chemicals. Chemical Review, 107, 2411-2502. https://doi.org/10.1021/cr050989d

Damstrup, M.L., Jensen, T., Sparsø, F.V., Kiil, S.Z., Jensen, A.D. and Xu, X. (2005). Solvent optimization for efficient enzymatic monoacylglycerol production based on a glycerolysis reaction. Journal of the American Oil Chemists Society, 82(8), 559-564. https://doi.org/10.1007/ s11746-005-1109-y

Devi, B.L.A.P., Zhang, H., Damstrup, M.L., Guo, Z., Zhang, L., Lue, B.M. and Xu, X. (2008). Enzymatic synthesis of designer lipids. OCL - Ol. Corps Gras Lipides, 15, 189-195. https://doi.org/10.1684/ ocl.2008.0194

Dhonsi, D. and Stapley, A.G.F. (2006). The effect of shear rate, temperature, sugar and emulsifier on the tempering of cocoa butter. Journal of Food Engineering, 77(4), 936-942. https:// doi.org/10.1016/j.jfoodeng.2005.08.022

Feltes, M.M.C., de Oliveira, D., Block, J.M. and Ninow, J.L. (2013). The Production, Benefits, and Applications of Monoacylglycerols and Diacylglycerols of Nutritional Interest. Food Bioprocess Technology, 6(1), 17-35. https:// doi.org/10.1007/s11947-012-0836-3

Ferrão, P., Lacarrière, B. and Corre, O.Le. (2017). Utilization of Waste Glycerol from Biodiesel Process as a Substrate for Mono- , Di- , and Triacylglycerol Production. Energy Procedia, 138, 895-900. 
j.egypro.2017.10.130

Ferretti, C.A., Spotti, M.L. and Di Cosimo, J.I. (2018). Diglyceride-rich oils from glycerolysis of edible vegetable oils. Catalysis Today, 302, 233-241. https://doi.org/10.1016/j.cattod.2017.04.008

Ferro, A.C., Okuro, P.K., Badan, A.P. and Cunha, R.L. (2019). Role of the oil on glyceryl monostearate based oleogels. Food Research International, 120, 610-619.

https://doi.org/10.1016/ j.foodres.2018.11.013

Foubert, I., Vanhoutte, B. and Dewettinck, K. (2004). Temperature and concentration dependent effect of partial glycerides on milk fat crystallization. European Journal of Lipid Science and Technology, 106(8), 531-539. https://doi.org/10.1002/ ejlt.200400979

Fu, Y., Zhao, R., Zhang, L., Bi, Y., Zhang, H. and Chen, C. (2018). Influence of acylglycerol emulsifier structure and composition on the function of shortening in layer cake. Food Chemistry, 249, 213221. https://doi.org/10.1016/j.foodchem.2017.12.051

Goldberg, M., Thomas, D. and Legoy, M.-D. (1990). The control of lipase-catalysed transesterification and esterification reaction rates: Effects of substrate polarity, water activity and water molecules on enzyme activity. European Journal of Biochemistry, 190(3), 603-609. https://doi.org/10.1111/j.14321033.1990.tb15615.x

Gomes, T., Caponio, F., Bruno, G., Summo, C. and Paradiso, V.M. (2010). Effects of monoacylglycerols on the oxidative stability of olive oil. Journal of the Science of Food Agriculture, 90(13), 2228-2232. https://doi.org/10.1002/jsfa.4075

Gunstone, F.D. (1999). Enzymes as biocatalysts in the modification of natural lipids. Journal of the Science of Food Agriculture, 79(12), 1535-1549. https:// doi.org/10.1002/(SICI)1097-0010(199909)

79:12<1535::AID-JSFA430>3.0.CO;2-7

Hattori, K., Dupuis, B., Fu, B.X. and Edwards, N.M. (2015). Effects of monoglycerides of varying fatty acid chain length and mixtures there of on spongeand-dough breadmaking quality. Cereal Chemistry, 92(5), 481-486. https://doi.org/10.1094/CCHEM-1214-0267-R

Herrera, M.L., Falabella, C., Melgarejo, M. and Anon, M.C. (1998). Isothermal crystallization of hydrogenated sunflower oil: I. Nucleation. Journal of the American Oil and Chemists Society, 75(10), 1273-1280.

Kim, B.H. and Akoh, C.C. (2015). Recent Research Trends on the Enzymatic Synthesis of Structured Lipids. Journal of Food Science, 80(8), 1713-1724. https://doi.org/10.1111/1750-3841.12953

Kowalska, M., Zbikowska, A. and Kowalski, B. (2014). Enzymatically Modified Fats Based on Mutton Tallow and Rapeseed Oil Suitable for Fatty Emulsions. Journal of the American Oil and Chemists Society, 91(10), 1703-1710. https:// doi.org/10.1007/s11746-014-2512-4

Kristensen, J.B., $\mathrm{Xu}, \mathrm{X}$. and $\mathrm{Mu}, \mathrm{H} . \quad$ (2005). Diacylglycerol synthesis by enzymatic glycerolysis: Screening of commercially available lipases. Journal of the American Oil and Chemists Society, 82(5), 329-334. https://doi.org/10.1007/s1 1746-005-1074-5

Krüger, R.L., Valério, A., Balen, M., Ninow, J.L., Oliveira, J.V., de Oliveira, D. and Corazza, M.L. (2010). Improvement of mono and diacylglycerol production via enzymatic glycerolysis in tert-butanol system. European Journal of Lipid Science and Technology, 112(8), 921-927. https:// doi.org/10.1002/ejlt.200900253

Latip, R.A., Lee, Y.Y., Tang, T.K., Phuah, E.T., Tan, C.P. and Lai, O.M. (2013). Physicochemical properties and crystallisation behaviour of bakery shortening produced from stearin fraction of palmbased diacyglycerol blended with various vegetable oils. Food Chemistry, 141(4), 3938-3946. https:// doi.org/10.1016/j.foodchem.2013.05.114

Lo, S.K., Tan, C.P., Long, K., Yusoff, M.S.A. and Lai, O.M. (2008). Diacylglycerol oil-properties, processes and products: A review. Food Bioprocess Technology, 1, 223-233. https://doi.org/10.1007/ s11947-007-0049-3

Lopez-Martínez, A., Charó-Alonso, M.A., Marangoni, A.G. and Toro-Vazquez, J.F. (2015). Monoglyceride organogels developed in vegetable oil with and without ethylcellulose. Food Research International, 72, 37-46. https://doi.org/10.1016/ j.foodres.2015.03.019

Maruyama, J.M., Soares, F.A.S.D.M., D'Agostinho, N.R., Goncalves, M.I.A., Gioielli, L.A. and da Silva, R.C. (2014). Effects of Emulsifier Addition on the Crystallization and Melting Behavior of Palm Olein and Coconut Oil. Journal of Agricultural and Food Chemistry, 62, 2253-2263. https://doi.org/10.1021/ jf405221n

Mazzanti, G., Guthrie, S.E., Sirota, E.B., Marangoni, A.G. and Idziak, S.H.J. (2003). Orientation and phase transitions of fat crystals under shear. Crystal Growth and Design, 3, 721-725. https:// doi.org/10.1021/cg034048a

Naderi, M., Farmani, J. and Rashidi, L. (2018). Physicochemical and Rheological Properties and Microstructure of Canola oil as Affected by 
Monoacylglycerols. Nutrition and Food Sciience Research, 5(1), 31-40. https://doi.org/10.29252/ nfsr.5.1.31

Naderi, M., Farmani, J. and Rashidi, L. (2016). Structuring of Chicken Fat by Monoacylglycerols. Journal of the American Oil and Chemists Society, 93(9), 1221-1231. https://doi.org/10.1007/s11746016-2870-1

Naik, M.K., Naik, S.N. and Mohanty, S. (2014). Enzymatic glycerolysis for conversion of sunflower oil tofood based emulsifiers. Catalysis Today, 237, 145-149.

j.cattod.2013.11.005

Nderitu, S.M., Nawiri, M.P. and Nyambaka, H.N. (2018). Fortification of sunflower and palm oils using beta carotene extracted from. Food Research, 2(5), 437-442. https://doi.org/10.26656/fr.2017.2 (5). 080

Ng, S.P., Lai, O.M., Abas, F., Lim, H.K., Beh, B.K., Ling, T.C. and Tan, C.P. (2014). Compositional and thermal characteristics of palm olein-based diacylglycerol in blends with palm super olein. Food Research International, 55, 62-69. https:// doi.org/10.1016/j.foodres.2013.10.035

Nor Aini, I., Razali, I., Noor Lida, H.M.D., Miskandar, M.S. and Radzuan, J. (2002). Blending of Palm Oil and Palm Products with Other Oils and Fats for Food Applications. Oil Palm Bulletin, 45, 6-15.

Normah, I., Cheow, C.S. and Chong, C.L. (2014). Crystal habit during crystallization of RBDPO with the addition of Diacylglycerol (DAG): Effect of time and percentage of DAG added. International Food Research Journal, 21, 2045-2049.

Osborn, H.T. and Akoh, C.C. (2002). Structured Lipids Novel Fats with Medical, Nutraceutical, and Food Applications. Comprehensive Reviews in Food Science and Food Safety, 1(3), 93-103. https:// doi.org/10.1111/j.1541-4337.2002.tb00010.x

Paraskevopoulou, A., Donsouzi, S., Nikiforidis, C.V. and Kiosseoglou, V. (2015). Quality characteristics of egg-reduced pound cakes following WPI and emulsifier incorporation. Food Research International, 69, 72-79. https://doi.org/10.1016/ j.foodres.2014.12.018

Pawongrat, R., Xu, X. and H-Kittikun, A. (2008). Physico-enzymatic production of monoacylglycerols enriched with very-long-chain polyunsaturated fatty acids. Journal of the Science of Food and Agriculture, 88(2), 256-262. https:// doi.org/10.1002/jsfa.3081

Pawongrat, R., Xu, X. and H-Kittikun, A. (2007). Synthesis of monoacylglycerol rich in polyunsaturated fatty acids from tuna oil with immobilized lipase AK. Food Chemistry, 104(1), 251-258.

j.foodchem.2006.11.036

https://doi.org/10.1016/

Pérez-Martínez, J.D., Sánchez-Becerril, M., Marangoni, A.G., Toro-Vazquez, J.F., Ornelas-Paz, J.J. and Ibarra-Junquera, V. (2019). Structuration, elastic properties scaling, and mechanical reversibility of candelilla wax oleogels with and without emulsifiers. Food Research International, 122, 471-478. https:// doi.org/10.1016/j.foodres.2019.05.020

Phuah, E.T., Beh, B.K., Lim, C.S.Y., Tang, T.K., Lee, Y.Y. and Lai, O.M. (2016). Rheological properties, textural properties, and storage stability of palm kernel-based diacylglycerol-enriched mayonnaise. European Journal of Lipid Science and Technology, 118(2), 185-194. https://doi.org/10.1002/ ejlt.201400586

Phuah, E.T., Tang, T.K., Lee, Y.Y., Choong, T.S.Y., Tan, C.P. and Lai, O.M. (2015). Review on the Current State of Diacylglycerol Production Using Enzymatic Approach. Food Bioprocess Technology, 8(6), 1169-1186. https://doi.org/10.1007/s11947-015 $-1505-0$

Rocha-Amador, O.G., Gallegos-Infante, J.A., Huang, Q., Rocha-Guzman, N.E., Rociomoreno-Jimenez, M. and Gonzalez-Laredo, R.F. (2014). Influence of commercial saturated monoglyceride, mono-/ diglycerides mixtures, vegetable oil, stirring speed, and temperature on the physical properties of organogels. International Journal of Food Science, 2014, 1-8. https://doi.org/10.1155/2014/513641

Romain, V., Ngakegni-Limbili, A.C., Mouloungui, Z. and Ouamba, J.M. (2013). Thermal properties of monoglycerides from Nephelium Lappaceum L. oil, as a natural source of saturated and monounsaturated fatty acids. Industrial and Engineering Chemistry Research, 52, 14089-14098. https://doi.org/10.1021/ ie $401875 \mathrm{v}$

Rønholt, S., Mortensen, K. and Knudsen, J.C. (2013). The effective factors on the structure of butter and other milk fat-based products. Comprehensive Reviews in Food Science and Food Safety, 12(5), 468-482. https://doi.org/10.1111/1541-4337.12022

Saberi, A.H., Tan, C.-P. and Lai, O.-M. (2011). Phase Behavior of Palm Oil in Blends with Palm-Based Diacylglycerol. Journal of the American Oil and Chemists Society, 88(12), 1857-1865. https:// doi.org/10.1007/s11746-011-1860-6

Saberi, A.H., Kee, B.B., Oi-Ming, L. and Miskandar, M.S. (2011). Physico-chemical properties of various palm-based diacylglycerol oils in comparison with their corresponding palm-based oils. Food 
Chemistry, 127(3), 1031-1038. https:// doi.org/10.1016/j.foodchem.2011.01.076

Saberi, A.H., Lai, O.M. and Miskandar, M.S. (2012). Melting and Solidification Properties of Palm-Based Diacylglycerol, Palm Kernel Olein, and Sunflower Oil in the Preparation of Palm-Based DiacylglycerolEnriched Soft Tub Margarine. Food Bioprocess Technology, 5(5), 1674-1685. https:// doi.org/10.1007/s11947-010-0475-5

Schantz, B. and Rohm, H. (2005). Influence of lecithinPGPR blends on the rheological properties of chocolate. LWT - Food Science and Technology, 38 (1), 41-45. https://doi.org/10.1016/j.lwt.2004.03.014

Shakerardekani, A., Karim, R., Ghazali, H.M. and Chin, N.L. (2013). The effect of monoglyceride addition on the rheological properties of pistachio spread. Journal of the American Oil and Chemists Society, 90(10), 1517-1521. https://doi.org/10.1007/s11746013-2299-8

Smith, K.W., Bhaggan, K., Talbot, G. and Van Malssen, K.F. (2011). Crystallization of fats: Influence of minor components and additives. Journal of the American Oil and Chemists Society, 88(8), 10851101. https://doi.org/10.1007/s11746-011-1819-7

Subroto, E., Hidayat, C. and Supriyadi. (2008). Enzymatic Interesterification of Fish Oil with Lauric Acid for the Synthesis of Structured Lipid. Jurnal Teknologi dan Industri Pangan, XIX, 105-112.

Subroto, E., Supriyanto, Utami, T. and Hidayat, C. (2019). Enzymatic glycerolysis-interesterification of palm stearin-olein blend for synthesis structured lipid containing high mono- and diacylglycerol. Food Science and Biotechnology, 28, 511-517. https://doi.org/10.1007/s10068-018-0462-6

Subroto, E., Tensiska, T., Indiarto, R., Marta, H. and Wulan, A.S. (2018). Physicochemical and sensorial properties of recombined butter produced from milk fat and fish oil blend. Bioscience Research, 15, 3733 -3740 .

Subroto, E., Wisamputri, M.F., Utami, T. and Hidayat, C. (2020). Enzymatic and chemical synthesis of high mono- and diacylglycerol from palm stearin and olein blend at different type of reactor stirrers. Journal of the Saudi Society of Agricultural Science, 19(1), 31-36. https://doi.org/10.1016/ j.jssas.2018.05.003

Taguchi, H., Nagao, T., Watanabe, H., Onizawa, K., Matsuo, N., Tokimitsu, I. and Itakura, H. (2001). Energy value and digestibility of dietary oil containing mainly 1,3-diacylglycerol are similar to those of triacylglycerol. Lipids, 36(4), 379-382. https://doi.org/10.1007/s11745-001-0731-7
Torres, C.F., Munir, F., Blanco, R.M. and Otero, C. (2002). Catalytic transesterification of corn oil and tristearin using immobilized lipases from thermomyces lanuginosa. Journal of the American Oil and Chemists Society, 79(8), 775-781. https:// doi.org/10.1007/s11746-002-0558-7

Tripathi, V., Trivedi, R. and Singh, R.P. (2006). LipaseCatalyzed synthesis of Diacylglycerol and Monoacylglycerol from unsaturated fatty acid in organic solvent system. Journal of Oleo Science, 55 (2), 65-69. https://doi.org/10.5650/jos.55.65

Valério, A., Krüger, R.L., Ninow, J., Corazza, F.C., De Oliveira, D., Vladimir Oliveira, J. and Corazza, M.L. (2009). Kinetics of solvent-free lipase-catalyzed glycerolysis of olive oil in surfactant system. Journal of Agriculture and Food Chemistry, 57, 8350-8356. https://doi.org/10.1021/jf901771m

Villeneuve, P., Muderhwa, J.M., Graille, J. and Haas, M.J. (2000). Customizing lipases for biocatalysis: A survey of chemical, physical and molecular biological approaches. Journal of Molecular Catalysis - B Enzymatic, 9(4-6), 113-148. https:// doi.org/10.1016/S1381-1177(99)00107-1

Wang, W., Li, T., Ning, Z., Wang, Y., Yang, B. and Yang, X. (2011). Production of extremely pure diacylglycerol from soybean oil by lipase-catalyzed glycerolysis. Enzyme and Microbial Technology, 49 (2), 192-196. https://doi.org/10.1016/ j.enzmictec.2011.05.001

Wang, Y., Zhao, M., Song, K., Wang, L., Han, X., Tang, S. and Wang, Y. (2010). Separation of diacylglycerols from enzymatically hydrolyzed soybean oil by molecular distillation. Separation and Purification Technology, 75(2), 114-120. https:// doi.org/10.1016/j.seppur.2010.08.012

Whitaker, S.R. (1994). Principles of Enzymology for The Food Science. Marcel Dekker, Inc, New York.

Willis, W.M. and Marangoni, A.G. (2002). Enzymatic Interesterification, in: Akoh, C.C., Min, D.B. (Eds.), Food Lipids Chemistry, Nutrition and Biotechnology. Marcel Dekker, Inc, New York.

Xu, Y., Zhao, X., Wang, Q., Peng, Z. and Dong, C. (2016). Thermal profiles, crystallization behaviors and microstructure of diacylglycerol-enriched palm oil blends with diacylglycerol-enriched palm olein. Food Chemistry, 202, 364-372. https:// doi.org/10.1016/j.foodchem.2016.01.102

Yang, T., Fruekilde, M.B. and Xu, X. (2003). Applications of Immobilized Thermomyces Ianuginosa Lipase in Interesterification. Journal of the American Oil and Chemists Society, 80(2), 881887. https://doi.org/10.1007/s11746-003-0789-7 
Yang, T., Rebsdorf, M., Engelrud, U. and Xu, X. (2005). Enzymatic production of monoacylglycerols containing polyunsaturated fatty acids through an efficient glycerolysis system. Journal of Agriculture and Food Chemistry, 53, 1475-1481. https:// doi.org/10.1021/jf048405g

Yeoh, C.M., Phuah, E.T., Tang, T.K., Siew, W.L., Abdullah, L.C. and Choong, T.S.Y. (2014). Molecular distillation and characterization of diacylglycerol-enriched palm olein. European Journal of Lipid Science and Technology, 116(12), 1654-1663. https://doi.org/10.1002/ejlt.201300502

Yilmaz, E. and Öğütcü, M. (2014). Properties and stability of hazelnut oil organogels with beeswax and monoglyceride. Journal of the American Oil and Chemists Society, 91(6), 1007-1017. https:// doi.org/10.1007/s11746-014-2434-1

Zhang, Y., Wang, X., Xie, D., Zou, S., Jin, Q. and Wang, X. (2018). Synthesis and concentration of 2monoacylglycerols rich in polyunsaturated fatty acids. Food Chemistry, 250, 60-66. https:// doi.org/10.1016/j.foodchem.2018.01.027

Zhang, Z., Ma, X., Huang, H., Li, G. and Wang, Y. (2017). Enzymatic Production of Highly Unsaturated Monoacyglycerols and Diacylglycerols and Their Emulsifying Effects on the Storage Stability of a Palm Oil Based Shortening System. Journal of the American Oil and Chemists Society, 94(9), 1175-1188. https://doi.org/10.1007/s11746017-3023-x

Zhang, Z., Wang, Y., Ma, X., Wang, E., Liu, M. and Yan, R. (2014). Characterisation and oxidation stability of monoacylglycerols from partially hydrogenated corn oil. Food Chemistry, 173, 70-79. https://doi.org/10.1016/j.foodchem.2014.09.155 